\title{
Physical processes dominate in shaping invertebrate assemblages in reef-associated sediments of an exposed Hawaiian coast
}

\author{
Ralph C. DeFelice ${ }^{1}$, James D. Parrish ${ }^{2, *}$ \\ ${ }^{1}$ Hawaii Cooperative Fishery Research Unit, University of Hawaii, 2538 The Mall, Honolulu, Hawaii 96822, USA \\ ${ }^{2}$ Hawaii Cooperative Fishery Research Unit, US Geological Survey, 2538 The Mall, Honolulu, Hawaii 96822, USA
}

\begin{abstract}
The invertebrate assemblages in sediments bordering exposed fringing reefs at Hanalei Bay, Kauai, Hawaii, were examined during July to September 1994. Densities of invertebrate animals larger than $0.5 \mathrm{~mm}$ in sediments of the bay ranged from counts of $10260 \mathrm{~m}^{-2}$ in the fine carbonate sands of the central bay to $870 \mathrm{~m}^{-2}$ in the habitat dominated by terrigenous silt near the reef edge close to the Hanalei river mouth. Similar sediment types supported broadly similar infaunal communities. Within the primarily carbonate sediments, mean grain size and wave exposure appear to have an important influence on the community. Taxonomic richness, number of individuals, and diversity showed significant negative relationships with exposure to wave energy (as estimated by sand ripple wavelength). The number of individuals was also significantly correlated with mean grain size. Overall, polychaetes and small crustaceans were numerically dominant among the major taxonomic groups investigated. Macrophagous and microphagous polychaetes had significant, but opposite, associations with grain size. In addition, microphagous polychaetes were significantly negatively correlated with wave exposure. No habitat variable measured could explain the variation in percent composition of crustaceans or echinoderms in the sedimentary habitats. The percentage of gastropods in the community was significantly negatively correlated with grain size, grain-size standard deviation and exposure, and positively with percent organic carbon. Bivalves were significantly positively associated with depth and grain size. These strong relationships imply that, in Hanalei Bay, physical processes are especially important in influencing assemblage structure, and that community structure and composition vary continuously along environmental gradients.
\end{abstract}

KEY WORDS: Wave exposure $\cdot$ Sand ripple wavelength $\cdot$ Sediment grain size $\cdot$ Environmental gradients $\cdot$ Numerical abundance $\cdot$ Diversity $\cdot$ Carbonate sediments

\section{INTRODUCTION}

Carbonate sediments of coral reefs generally cover a greater area than hard substrates in tropical shallow waters (Thomassin 1978). These sediments and their related fauna have received relatively less attention than hard substrate systems, but are known to support diverse invertebrate assemblages (Taylor 1971, Hughes \&

\footnotetext{
*Corresponding author. E-mail: parrishj@hawaii.edu
}

Gamble 1977, Birtles \& Arnold 1983, Jones 1984, Brown \& McLachlan 1990). Quantitative studies of invertebrates at the community level in coral reef sands are few (Aller \& Dodge 1974, Thomassin et al. 1976, 1982, Bailey-Brock 1979, 1984, Riddle 1988, Villiers 1988), and factors that influence species composition and community structure in reef-associated sediments are poorly understood.

Physical characteristics of sediment, such as grain size or sediment type, are often identified as important determinants of community structure and faunal distri- 
bution (Probert 1984, Riddle 1988, St. John et al. 1989). Invertebrate diversity patterns may be related to sediment sorting (Riddle 1988). In temperate marine systems, invertebrate assemblages may also be influenced by organic carbon levels in the sediment (Gray 1981, Whitlach 1981), but researchers in tropical systems have found little correlation between organic content and community structure (Jones 1984).

Most investigations of invertebrates in coral reef sediments have been conducted within protected lagoons or backreef areas insulated from the direct effects of ocean swell. In such areas of low exposure, it appears that biological processes, especially direct predation or disturbance caused by predation, are important in structuring communities (Sherman et al. 1983, Suchanek \& Colin 1986, Jones et al. 1990, 1992). Competition, food availability and biogenic alteration of sediment properties may also be important in softbottom habitats in protected areas (Bailey-Brock 1979, Woodin 1983, Probert 1984, Pearson \& Rosenberg 1986).

Where disturbance by physical processes is severe or frequent, biotic influence on benthic communities may be relatively less important (Probert 1984). The influence of exposure to wave energy has been considered in temperate systems. Wave energy may provide a mechanism for zonation of benthic invertebrate communities (Oliver et al. 1980). Riddle (1988) compared sediment fauna from reefs under different environmental conditions and concluded that within-reef differences in fauna were related to the type of sediment and the degree of exposure to wave energy. McCarthy (1996), however, found no evidence that large wave events or freshwater runoff influence density and composition of soft-bottom benthic assemblages on Oahu.

In Hawaii, investigation of reef-associated sediment communities has been limited (Bailey-Brock 1979, 1984, Sorden 1982, Brock \& Smith 1983, McCarthy 1996). This study examines the physical characteristics of near-reef sediments in Hanalei Bay, Kauai, and the taxonomic composition and community structure of their invertebrate assemblages, and investigates the relationships between invertebrate assemblage structure and habitat variables.

\section{MATERIALS AND METHODS}

Study site. The study was conducted on the north (windward) shore of Kauai, in Hanalei Bay (Fig. 1). The bay is associated with 4 watersheds (Hanalei Estuary and 3 small streams) and receives freshwater input from each. The center of the bay is made up of sediments that stretch from the shoreline in the southeast quadrant to beyond the mouth of the bay. Substrates on the west and northeast sides of the bay consist mostly of various types of reef habitat, with scattered sand patches, that extend beyond the mouth of the bay.

Sediment sampling. Nine sampling stations were permanently established in the soft-bottom habitats of Hanalei Bay (Fig. 1) and were marked by driving $1.5 \mathrm{~m}$ stakes into the sand. Locations of the sampling stations were based on preliminary surveys of the distribution of sediment types. Stations associated with reef edges were located $50 \mathrm{~m}$ from the reef/sand interface of the closest hard substrate.

Sediment samples were collected using SCUBA with a $15.5 \mathrm{~cm}$ diam. corer $\left(0.019 \mathrm{~m}^{2}\right.$ area $)$ pushed manually to a depth of $15 \mathrm{~cm}$. Five samples were taken at each site in conjunction with infaunal collections (see next section) and sediment samples were later stored at $-18^{\circ} \mathrm{C}$. Samples were dried at $65^{\circ} \mathrm{C}$, and a subsample of approximately $175 \mathrm{~g}$ from each core was sorted into $0.5 \phi$ fractions ( $\phi=-\log _{2}$ [grain diam. in $\mathrm{mm}$ ]) by shaking for 10 min through a graded series of sieves on a geological sieve shaker. Each sieve fraction was weighed separately to determine sediment grain-size frequency distributions and resulting sand:silt ratios. The 'silt' fraction, which may contain a mixture of coarse silt, silt, and clay, includes all sediments with $\phi$ values $>4.0(<0.0625 \mathrm{~mm}$ diam. $)$.

Statistical parameters of grain size (e.g. mean grain size and standard deviation) were calculated following the method of moments procedure (Lindholm 1987). The standard deviation provides information on the extent to which particle sizes cluster about the mean, thus describing the sample sorting. Total organic carbon and percentage of calcium carbonate were determined using a C-H-N analyzer and loss of weight upon ignition.

The wavelengths of sand ripples were measured at each sampling station, and the mean ripple wavelength was used as an index of exposure to wave energy. After the threshold of sediment movement is exceeded, the ripple wavelength $(\lambda)$ is related to the near-bottom orbital diameter (or orbital excursion) $\left(d_{0}\right)$ of water particles through $\lambda=0.65 d_{0}$. The $d_{\mathrm{o}}$ of the to and fro near-bottom water motion is related to the surface wave height $(H)$ and length $(L)$, and to the water depth $(h)$ through the relationship:

$$
d_{\mathrm{o}}=\frac{H}{\sinh \left(\frac{2 \pi h}{L}\right)}
$$

The maximum velocity, $u_{\mathrm{m}}$, attained by near-bottom water particles determines the orbital diameter and is calculated from:

$$
u_{\mathrm{m}}=\frac{\pi d_{\mathrm{o}}}{T}
$$


Fig. 1. The Island of Kauai (inset), locations of soft-bottom sampling stations (1-9) and sedimentary habitat types identified in Hanalei Bay

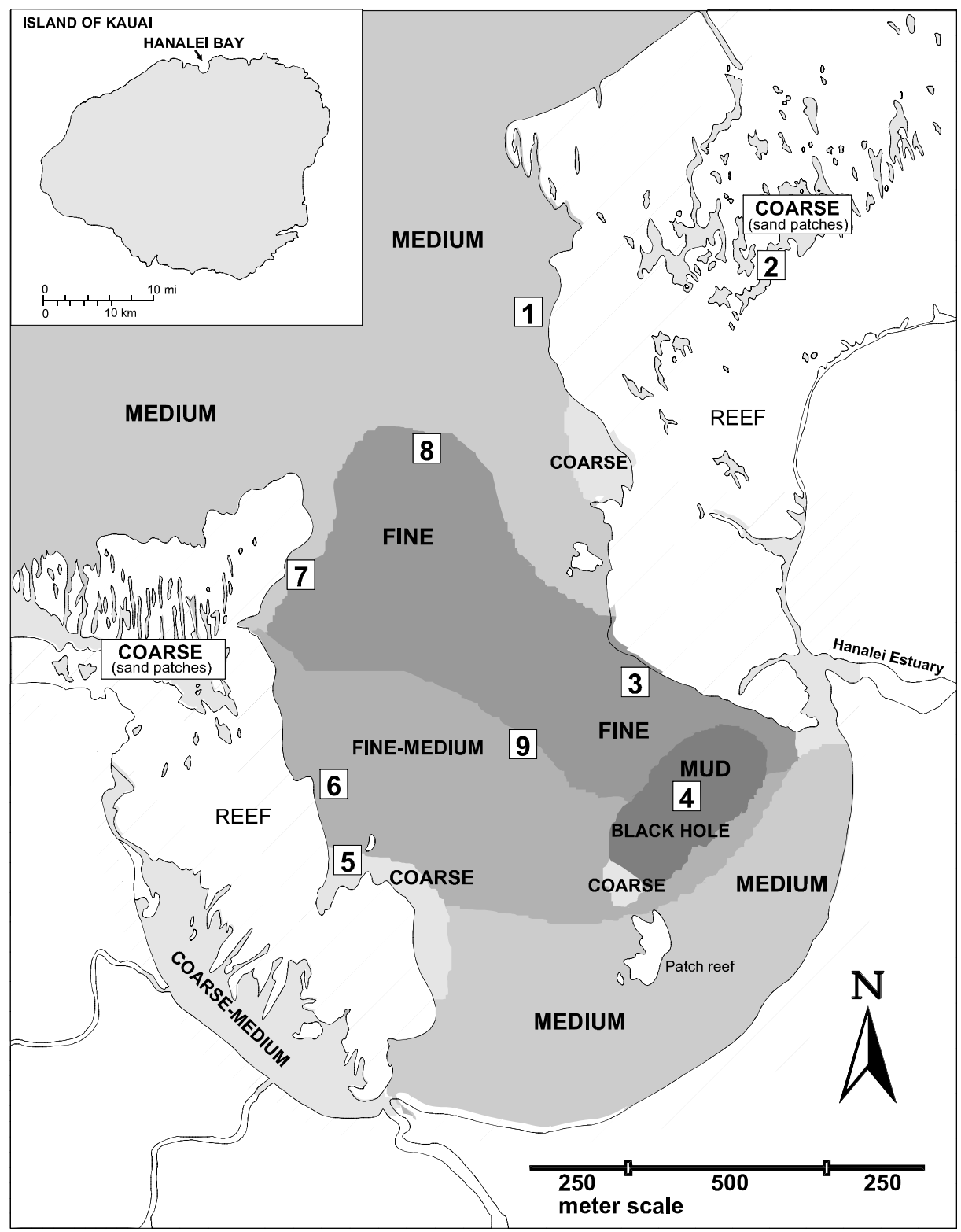

where $T$ is equal to the period of the surface waves. Therefore, surface water waves of greater height $(H)$ and length $(L)$ produce greater orbital water velocity at the bottom, and thus greater disturbance of sediments, leaving a bottom signature characterized by greater length $(\lambda)$ of sediment ripples (Miller \& Komar 1980, Davies 1984).

Faunal sampling by coring. The distribution, community structure and taxonomic composition of invertebrate communities in the soft-bottom habitats of Hanalei Bay were described based on core samples of invertebrates taken at the 9 permanent stations during July to September 1994. Invertebrates were sampled using a hand-held corer of $15.5 \mathrm{~cm}$ diam. $\left(0.019 \mathrm{~m}^{2}\right.$ area) pushed to a depth of $15 \mathrm{~cm}$. At each station, a $5 \times$ $5 \mathrm{~m}$ quadrat was established with a grid defined by $0.5 \mathrm{~m}$ intervals marked along each axis. For each sampling occasion, 10 grid points of intersection were chosen by reference to a random numbers table, and a single core was taken at each point.

The coring device and the sample it contained were placed in a $19 \mathrm{l}$ plastic bag under water to minimize the chance of escape by motile animals. In the boat, the samples were separated from the corer and double-bagged. The entire sample was fixed with $10 \%$ formalin.

Invertebrates were separated from the sediment by elutriation. Each sample was washed by slowly swir- 
Table 1. Variables used in stepwise multiple linear regression analysis of invertebrate assemblages

\begin{tabular}{|c|c|c|}
\hline Variable & Units & $\begin{array}{l}\text { Transfor- } \\
\text { mation }\end{array}$ \\
\hline \multicolumn{3}{|l|}{ Independent } \\
\hline Water depth & $\mathrm{m}$ & none \\
\hline Grain size & $\phi$ & none \\
\hline SD (of grain size) & index & none \\
\hline Organic carbon & $\%^{\mathrm{a}}$ & none \\
\hline Ripple wavelength & $\mathrm{cm}$ & $\log _{10}$ \\
\hline \multicolumn{3}{|l|}{ Dependent } \\
\hline Mean no. of taxa & number & none \\
\hline Mean no. of ind. & number & $\log _{10}$ \\
\hline Mean diversity & index & none \\
\hline Mean evenness & index & none \\
\hline Macrophagous polychaetes & $\%^{\mathrm{b}}$ & arcsin sqrt \\
\hline Microphagous polychaetes & $\%$ & arcsin sqrt \\
\hline Crustaceans & $\%$ & arcsin sqrt \\
\hline Gastropods & $\% \mathrm{~b}$ & arcsin sqrt \\
\hline Bivalves & $\%^{\mathrm{b}}$ & arcsin sqrt \\
\hline Echinoderms & $\%$ & arcsin sqrt \\
\hline $\begin{array}{l}{ }^{a} \text { Percent of total dry wt of sedi } \\
\text { b Percent of total no. of ind. }\end{array}$ & & \\
\hline
\end{tabular}

ling in a shallow tray, and the animals were decanted and retained on a $500 \mu \mathrm{m}$ sieve. This process was repeated $6 \times$ for each sample. After elutriation, the remaining sediment was washed through the $500 \mu \mathrm{m}$ sieve. The remaining fraction was examined under a dissecting microscope for heavier animals (e.g. worms in sand tubes and large molluscs) not readily separated from the sediments by elutriation. All invertebrates were enumerated and identified to family level or lower.

Sample optimization. To select an appropriate sample size to accommodate the variability in spatial distribution of benthic invertebrates, the behavior of the variance of the total number of individuals was examined as a function of sample size. Ten closely spaced $15.5 \mathrm{~cm}$ diam. cores were collected from Stn 1 and the total count of invertebrate animals in each was made. These 10 elemental samples were then combined randomly in groups of $2,3,4,5,6,7,8,9$ and 10, and the mean and standard error of the mean (SEM) were calculated for each combination. These SEM's, when plotted against the number of cores, displayed a nearly monotonic decline, approaching an asymptote at $\sim 10$ samples. The result suggests that the variability in the estimate of the mean had largely stabilized with a sample comprising about 7 cores.

Similarly, the species-area curve for Stn 1 approached an asymptote near 7 cores. The data and discussion below are the results of analysing 10 core samples per station. The analysis of cores from several stations using the procedure outlined by Andrew \& Mapstone
(1987) indicated that 10 cores per station provided a level of precision of about 0.07 .

Data analysis. Spearman's rank order correlation coefficients for habitat and community variables were calculated, and several habitat variables were then examined as predictors of ensemble properties and community composition of the invertebrate assemblages in the carbonate sediments using backward elimination stepwise multiple linear regression analysis (SAS 1996). Because of the limited number of degrees of freedom, no interaction terms of independent variables were explored. Dependent and independent variables and their transformations are listed in Table 1.

Diversity (Shannon-Wiener $\log _{\mathrm{e}}$ ) and evenness (Pielou) indices and Spearman's rank order correlation coefficients were calculated using the MultiVariate Statistical Package (MVSP Plus, version 2.1) (Pielou 1977, Kovach 1993). The regression procedures used are components of the SAS/STAT software package (SAS 1996).

\section{RESULTS}

\section{Sediments}

A wide range of sediment types was found in Hanalei Bay (Table 2). Sediments at all stations were devoid of coral rubble. The shallow sand-patch station (Stn 2) had the largest mean grain size $(\phi=0.59)$, the lowest percent silt $(0.01 \%)$, poor particle sorting (SD = $2.0)$ and the highest percent carbonate $(92.40 \%)$. The muddy station (Stn 4) contained fine sediments (mean $\phi=3.52$ ) with a $38.19 \%$ silt fraction. High levels of organic carbon $(4.02 \%)$ and low levels of carbonate $(21.36 \%)$ were associated with this sediment type. Sediments elsewhere in the bay were of medium to fine grain size with moderate to poorly sorted particles. Their low organic carbon levels (0.16 to $0.85 \%$ ) and their range of percent carbonate (55.63 to $84.56 \%$ ) were typical of reef-associated sediments.

Sedimentary variables were analyzed for correlations with one another to suggest important relationships between abiotic characteristics of the habitat (Table 3). Carbonate and mean $\phi$ were perfectly correlated $\left(r_{s}=-1.00, p<0.001\right)$. Because $\phi$ is a negative logarithmic function of grain size, a strong positive relationship exists between carbonate and mean grain size. Therefore, the larger grains tended to be of marine biological origin. The strong negative correlation between carbonate and percentage of silt $\left(\mathrm{r}_{\mathrm{s}}=\right.$ $-0.97, \mathrm{p}<0.01)$, the strong positive correlation $\left(\mathrm{r}_{\mathrm{s}}=\right.$ 0.97, $\mathrm{p}<0.01$ ) between percentage of silt and mean $\phi$, and the strong negative correlation $\left(\mathrm{r}_{\mathrm{s}}=-0.97, \mathrm{p}<\right.$ 
Table 2. Sediment data for Hanalei Bay permanent stations

\begin{tabular}{|c|c|c|c|c|c|c|c|c|}
\hline Station & $\begin{array}{l}\text { Water depth } \\
\text { (m) }\end{array}$ & $\begin{array}{l}\text { Grair } \\
\text { Mean }(\phi)\end{array}$ & $\mathrm{SD}$ & $\begin{array}{l}\text { Sand } \\
(\%)\end{array}$ & $\begin{array}{l}\text { Silt } \\
(\%)\end{array}$ & $\begin{array}{c}\text { Organic } \\
\text { carbon }(\%)\end{array}$ & $\begin{array}{c}\mathrm{CaCO}_{3} \\
(\%)\end{array}$ & $\begin{array}{l}\text { Ripple wave- } \\
\text { length }(\mathrm{cm})\end{array}$ \\
\hline 1 & 20.40 & 1.98 & 0.95 & 99.19 & 0.81 & 0.16 & 84.56 & 7.3 \\
\hline 2 & 8.60 & 0.59 & 2.00 & 99.99 & 0.01 & 0.39 & 92.40 & 72.3 \\
\hline 3 & 10.70 & 2.61 & 0.62 & 98.46 & 1.54 & 0.85 & 65.05 & 5.1 \\
\hline 4 & 12.50 & 3.52 & 1.46 & 61.81 & 38.19 & 4.02 & 21.36 & 0.0 \\
\hline 5 & 10.10 & 1.20 & 1.45 & 99.58 & 0.42 & 0.50 & 90.00 & 48.7 \\
\hline 6 & 12.20 & 2.81 & 0.74 & 95.39 & 4.61 & 0.50 & 60.91 & 11.4 \\
\hline 7 & 17.70 & 2.31 & 0.63 & 99.42 & 0.58 & 0.82 & 76.71 & 16.7 \\
\hline 8 & 18.90 & 2.93 & 1.04 & 90.13 & 9.87 & 0.75 & 55.63 & 4.5 \\
\hline 9 & 12.50 & 2.82 & 0.77 & 96.54 & 3.46 & 0.52 & 56.20 & 10.8 \\
\hline
\end{tabular}

0.01) between percentage of sand and mean $\phi$ are measures of the same characteristic. Percentage of silt and percentage of sand are perfectly negatively correlated by definition. Although not significant, there is a strong suggestion that higher organic carbon levels are associated with finer sediments (i.e. positively with $\phi$ size and silt, negatively with sand). No sedimentary variables showed a significant association with water depth, but the degree to which stations were exposed to wave energy (measured by sand ripple wavelength) was significantly correlated with mean $\phi\left(\mathrm{r}_{\mathrm{s}}=-0.82\right.$, $\mathrm{p}<$ 0.05) and therefore also with the percentage of sand, silt and carbonate.

Fifty additional sediment samples were taken at various locations throughout Hanalei Bay to examine the distribution of unique sedimentary habitats (Fig. 1). Samples were assigned to sediment groups based on their mean grain size. Fine and medium-fine sands make up the majority of the sedimentary habitat of Hanalei Bay. Medium-fine sands are associated with reef edges in the outer bay and the shoreline. Fine sands are distributed throughout the central bay area. The most distinctive feature of the soft-bottom habitat of Hanalei Bay is the presence of a large silt/mud depression associated with the Hanalei River mouth, known locally as 'the Black Hole'. The center of this depression is approximately $8 \mathrm{~m}$ deeper than the sur- rounding fine sand habitat and appears to be an area of deposition for terrigenous material transported down the estuary. Large logs and smaller terrestrial plant debris litter the bottom. Because of its depth and location relative to the nearby reef, the area is relatively protected from wave energy. This muddy habitat appears to play an important ecological role for many fish species (DeFelice \& Parrish, unpubl.). Within the bay, coarse sands were present in all sand patches and along reef edges near Stn 5 and east of Stn 8. A small isolated area of coarse sand was present at the edge of the Black Hole, north of a small patch reef in the central bay.

\section{Invertebrate assemblages}

A total of 7119 individuals assigned to 77 taxa (23 polychaete, 26 crustacean, 15 molluscan, and 13 other) were collected in cores from the 9 sampling stations. The number of taxa collected in individual core samples ranged from 3 to 30, with a mean of 14.41. The number of individuals also varied greatly among cores (6 to $234, \bar{x}=80.96$ ). No taxon was found at every sampling station.

The mean number of taxa and individuals per core was highly variable among stations (Table 4). The

Table 3. Spearman's rank order correlation coefficients for abiotic variables of sediments. ${ }^{*} \mathrm{p}<0.05$

\begin{tabular}{|c|c|c|c|c|c|c|c|}
\hline & $\begin{array}{c}\text { Water } \\
\text { depth (m) }\end{array}$ & $\begin{array}{c}\text { Mean } \\
\text { grain size }(\phi)\end{array}$ & $\begin{array}{l}\mathrm{SD} \\
\text { grain size }\end{array}$ & $\begin{array}{l}\text { Sand } \\
(\%)\end{array}$ & $\begin{array}{l}\text { Silt } \\
(\%)\end{array}$ & $\begin{array}{c}\text { Organic } \\
\text { carbon (\%) }\end{array}$ & $\begin{array}{c}\mathrm{CaCO}_{3} \\
(\%)\end{array}$ \\
\hline Mean size $(\phi)$ & 0.43 & - & & & & & \\
\hline SD grain size & -0.23 & -0.13 & - & & & & \\
\hline Sand $(\%)$ & -0.44 & $-0.97^{*}$ & 0.10 & - & & & \\
\hline Silt $(\%)$ & 0.44 & $0.97^{*}$ & -0.10 & $-1.00^{*}$ & - & & \\
\hline Organic carbon (\%) & 0.08 & 0.67 & -0.28 & -0.54 & 0.54 & - & \\
\hline $\mathrm{CaCO}_{3}(\%)$ & -0.43 & $-1.00^{*}$ & 0.13 & $0.97^{*}$ & $-0.97^{*}$ & -0.67 & - \\
\hline Ripple $\lambda(\mathrm{cm})$ & -0.55 & $-0.82^{*}$ & 0.11 & $0.85^{*}$ & $-0.85^{*}$ & -0.59 & $0.82^{*}$ \\
\hline
\end{tabular}


Table 4. Values of community statistics for individual soft-bottom habitat stations. For 'Taxa' and 'Individuals', values are mean number per core. Values in parentheses are SD

\begin{tabular}{|lcrcccc|}
\hline Station & $\mathrm{n}$ & \multicolumn{1}{c}{ Taxa } & $\begin{array}{c}\text { Total } \\
\text { taxa }\end{array}$ & Individuals & Diversity & Evenness \\
\hline 1 & 10 & $19.1(2.6)$ & 40 & $82.9(21.0)$ & 2.76 & 0.749 \\
2 & 10 & $6.2(0.8)$ & 18 & $41.1(6.15)$ & 1.73 & 0.598 \\
3 & 10 & $20.1(2.3)$ & 42 & $87.7(22.5)$ & 2.80 & 0.748 \\
4 & 10 & $5.4(2.1)$ & 15 & $16.7(7.9)$ & 1.96 & 0.724 \\
5 & 10 & $13.3(1.7)$ & 41 & $64.1(15.1)$ & 2.23 & 0.609 \\
6 & 10 & $10.9(2.6)$ & 30 & $66.7(14.8)$ & 2.10 & 0.616 \\
7 & 10 & $13.5(3.4)$ & 38 & $48.5(10.4)$ & 2.66 & 0.732 \\
8 & 10 & $25.7(3.1)$ & 45 & $196.1(31.6)$ & 2.65 & 0.697 \\
9 & 10 & $15.3(2.0)$ & 40 & $124.8(9.8)$ & 1.81 & 0.489 \\
\hline
\end{tabular}

mean number of taxa was lowest at the shallow, coarse-grained sand patch station (Stn 2) and in the deeper, silty, depositional area (Stn 4). These 2 stations also contained the lowest numbers of individuals per core and were of low diversity. Relatively high mean numbers of taxa were collected at Stns 8 and 3. High diversity and high numbers of individuals were also associated with these fine-grained stations. Evenness did not vary greatly among most stations.

Individuals collected were separated into major taxonomic groups to investigate general similarities between stations. Polychaetes were divided into macroand microphagous groups according to Fauchald \& Jumars (1979) and Bailey-Brock (1987). Macrophages usually handle food particles singly, with all parts of the feeding apparatus involved in handling each separate particle. Microphages handle many particles at once, usually with each particle being handled by only a part of the feeding apparatus. Although there are exceptions, most macrophagous polychaetes are carnivores, omnivores or herbivores, while microphagous polychaetes are suspension- or deposit-feeders (surface or subsurface). This subdivision of the Polychaeta roughly corresponds to the arbitrary groupings Polychaeta Errantia and Polychaeta Sedentaria respectively (see Day 1967). In general, Polychaeta Errantia include families whose members have a pharynx armed with jaws or teeth, sensory appendages, and well developed parapodia. Polychaeta Sedentaria may be characterized by the lack of jaws or teeth, reduced or absent sensory appendages, and reduced parapodia. Both groups display a variety of motility patterns. In Hanalei Bay, microphagous polychaetes were predominantly paraonids, opheliids, spionids, and magelonids. Syllids and lumbrinerids were the numerically dominant macrophages.

Additional major taxonomic groups included crustaceans (Cl. Maxillopoda and Cl. Malacostraca), gastropods (Cl. Gastropoda), bivalves (Cl. Bivalvia), echinoderms (Cl. Ophiuroidea and $\mathrm{Cl}$. Echinoidea) and 'other' taxa. 'Other' taxa included sipunculans (Ph. Sipuncula), acorn worms (Cl. Enteropneusta), lancelets (SubPh. Cephalochordata) and fishes (Cl. Osteicthyes).

Macrophagous polychaetes were present in the highest numbers at Stns 5 and 2 (Table 5). At both stations, this group of polychaetes made up the majority of the total invertebrate population. The relative numerical abundance of macrophagous polychaetes was especially low at Stns 6 and 9, where they were about $1 \%$ of the total community. Microphagous polychaetes were most abundant at the 2 center stations (Stns 8 and 9). Very few microphages were collected in the sand patch at Stn 2. The absolute abundance of crustaceans was highest at the center stations, 8 and 9, but crustaceans were the greatest component of the community at Stn 2. Gastropods were a small percentage of the total community at all stations, and no gastropods were collected at Stn 2. Bivalves were highly abundant at Stn 8, but were absent at Stn 2 and present in low numbers at all other stations. No echinoderms were found at Stn 4; they were present in low relative abundance at all other stations except Stn 7 , where they made up $13.8 \%$ of the community. The abundance of other taxonomic groups was low at most stations. At Stn 4, however, sipunculans and acorn worms combined made up an important portion (>30\%) of the community.

\section{Associations of fauna with habitat variables in carbonate sediments}

Ensemble variables of the invertebrate community as a whole found in the carbonate sediments of Hanalei Bay and the percentages of all individuals represented by its major taxonomic groups were analyzed for correlations with habitat characteristics. Since the goal of this analysis was to investigate relationships between habitat and fauna in typical reef-associated carbonate sediments, Stn 4 was omitted from this analysis. A cluster analysis of stations by faunal composition clearly showed that this predominantly terrigenous sedimentary habitat $\left(<25 \% \mathrm{CaCO}_{3}\right)$ has a very different fauna from the other predominantly $(>50 \%$ ) carbonate sediment stations. Of all stations, Stn 4 had the lowest mean number of taxa per core, lowest total number of taxa and lowest number of individuals collected. More than $30 \%$ of the individuals collected from this station were included in the 'other' 
Table 5. Mean no. of individuals of major taxonomic groups per core at individual soft-bottom stations. Numbers in parentheses are percent of total no. of individuals (all taxa combined)

\begin{tabular}{|lccccccccc|}
\hline & & & & \multicolumn{7}{c}{ Station } & & & \\
& 1 & 2 & 3 & 4 & 5 & 6 & 7 & 8 & 9 \\
\hline Macrophagous polychaetes & 4.6 & 21.9 & 5.5 & 3.0 & 33.9 & 0.7 & 7.0 & 4.7 & 1.3 \\
& $(5.5)$ & $(53.3)$ & $(6.3)$ & $(18.0)$ & $(52.9)$ & $(1.0)$ & $(14.4)$ & $(2.4)$ & $(1.0)$ \\
Microphagous polychaetes & 31.9 & 0.3 & 40.5 & 6.9 & 7.6 & 33.7 & 15.9 & 102.4 & 67.7 \\
& $(38.5)$ & $(0.7)$ & $(46.2)$ & $(41.3)$ & $(11.9)$ & $(50.5)$ & $(32.8)$ & $(52.2)$ & $(54.2)$ \\
Crustaceans & 34.0 & 18.5 & 35.3 & 1.0 & 17.3 & 27.6 & 14.3 & 45.8 & 49.1 \\
& $(41.0)$ & $(45.0)$ & $(40.3)$ & $(6.0)$ & $(27.0)$ & $(41.4)$ & $(29.5)$ & $(23.4)$ & $(39.3)$ \\
Gastropods & 0.6 & 0.0 & 2.2 & 0.1 & 0.3 & 0.9 & 0.4 & 3.4 & 1.0 \\
Bivalves & $(0.7)$ & $(0.0)$ & $(2.5)$ & $(0.6)$ & $(0.5)$ & $(1.3)$ & $(0.8)$ & $(1.7)$ & $(0.8)$ \\
& 2.3 & 0.0 & 1.2 & 0.6 & 0.5 & 1.8 & 3.3 & 30.7 & 4.1 \\
Echinoderms & $(2.8)$ & $(0.0)$ & $(1.4)$ & $(3.6)$ & $(0.8)$ & $(2.7)$ & $(6.8)$ & $(15.7)$ & $(3.3)$ \\
& 6.7 & 0.1 & 0.4 & 0.0 & 3.2 & 0.8 & 6.7 & 6.1 & 0.8 \\
Other taxa & $(8.1)$ & $(0.2)$ & $(0.5)$ & $(0.0)$ & $(5.0)$ & $(1.2)$ & $(13.8)$ & $(3.1)$ & $(0.6)$ \\
& 2.8 & 0.3 & 2.6 & 5.1 & 1.3 & 1.2 & 0.9 & 3.0 & 1.0 \\
Total & $(3.4)$ & $(0.7)$ & $(3.0)$ & $(30.5)$ & $(2.0)$ & $(1.8)$ & $(1.9)$ & $(1.5)$ & $(0.8)$ \\
& 82.9 & 41.1 & 87.7 & 16.7 & 64.1 & 66.7 & 48.5 & 196.1 & 124.8 \\
\hline
\end{tabular}

taxa category, compared to $0.7-3.4 \%$ at other stations. In addition, the sediments at Stn 4 had by far the highest percentage of silt and organic carbon content. Because of these outlying values for both faunal and sediment variables, interpretation of this aberrant habitat was not attempted in conjunction with the carbonate habitats.

For the carbonate sediments, significant relationships were found between habitat and community variables (Table 6). Number of taxa (S) and number of individuals (n) were strongly negatively correlated with sand ripple wavelength $\left(r_{\mathrm{s}}=-0.93\right.$ and $\left.\mathrm{r}_{\mathrm{s}}=-0.90\right)$. The number of individuals was positively correlated with mean $\phi\left(r_{\mathrm{s}}=0.83\right)$, and therefore negatively with mean grain size. Diversity $\left(\mathrm{H}^{\prime}\right)$ and evenness $(\mathrm{J})$ were not significantly correlated with habitat variables, but there was some indication of a positive relationship between diversity and depth $\left(\mathrm{r}_{\mathrm{s}}=0.71\right)$ and a negative relationship between diversity and sand ripple wavelength $\left(\mathrm{r}_{\mathrm{s}}=-0.71\right)$.

The percent composition of macrophagous polychaetes was negatively correlated with mean $\phi\left(\mathrm{r}_{\mathrm{s}}=\right.$
-0.86). Microphagous polychaetes were strongly positively correlated with mean $\phi\left(r_{s}=0.95\right)$ and somewhat negatively associated with sand ripple wavelength $\left(\mathrm{r}_{\mathrm{s}}=\right.$ -0.74). Gastropods were significantly positively correlated with mean $\phi\left(\mathrm{r}_{\mathrm{s}}=0.76\right)$ and percent carbon $\left(\mathrm{r}_{\mathrm{s}}=\right.$ 0.77 ) and negatively correlated with the standard deviation of the grain size distribution $\left(\mathrm{r}_{\mathrm{s}}=-0.74\right)$ and sand ripple wavelength $\left(r_{\mathrm{s}}=-0.76\right)$. Bivalves were significantly positively correlated with depth $\left(\mathrm{r}_{\mathrm{s}}=0.85\right)$ and mean $\phi\left(r_{s}=0.74\right)$. Crustaceans and echinoderms showed no significant relationships with habitat variables.

Multiple linear regression analysis indicates that exposure to wave energy is an important factor in structuring the invertebrate communities in carbonate sediments in Hanalei Bay (Table 7). The mean number of taxa, individuals and diversity were significantly negatively associated with sand ripple wavelength. Exposure explained over $71 \%$ of the variability in mean number of taxa per core sample among stations, $56 \%$ in mean number of individuals, and nearly $63 \%$ in mean diversity. Although several other habitat variables may make small contributions to further explain

Table 6. Spearman's rank order correlation coefficients for abiotic variables and community variables. $\mathrm{S}=\mathrm{no}$. of taxa; $\mathrm{n}=$ no. of individuals; $\mathrm{H}^{\prime}=$ diversity; $\mathrm{J}=$ evenness; Macro = macrophagous polychaetes; Micro = microphagous polychaetes; $\mathrm{Cr}=$ crustaceans; Gas = gastropods; Biv = bivalves; $\mathrm{Ech}=$ echinoderms. All values are mean per core sample. For each taxonomic group, the variable in the analysis was its no. of individuals as a percentage of all individuals. ${ }^{*} \mathrm{p}<0.05$

\begin{tabular}{|lccrrrrrrrr}
\hline & $\mathrm{S}$ & $\mathrm{n}$ & $\mathrm{H}^{\prime}$ & $\mathrm{J}$ & Macro & Micro & Cr & Gas & Biv & Ech \\
\hline Water depth (m) & 0.64 & 0.52 & 0.71 & 0.24 & -0.55 & 0.50 & -0.33 & 0.33 & $0.85^{*}$ & 0.64 \\
Mean $\phi$ & 0.60 & $0.83^{*}$ & 0.21 & -0.36 & $-0.86^{*}$ & $0.95^{*}$ & -0.40 & $0.76^{*}$ & $0.74^{*}$ & -0.02 \\
SD & -0.33 & -0.24 & -0.26 & -0.36 & 0.38 & -0.40 & 0.00 & $-0.74^{*}$ & -0.33 & -0.12 \\
Carbon (\%) & 0.49 & 0.34 & 0.18 & -0.05 & -0.13 & 0.36 & -0.52 & $0.77^{*}$ & 0.41 & -0.02 \\
Ripple $\lambda(\mathrm{cm})$ & $-0.93^{*}$ & $-0.90^{*}$ & -0.71 & -0.17 & 0.62 & $-0.74^{*}$ & 0.33 & $-0.76^{*}$ & -0.60 & -0.05 \\
& & & & & & & & & \\
\hline
\end{tabular}


Table 7. Statistically significant results of 4 stepwise multiple linear regression analyses for dependent ensemble variables as functions of independent habitat variables. (Habitat variables listed in Table 6.)

\begin{tabular}{|c|c|c|c|c|c|}
\hline $\begin{array}{l}\text { Dependent } \\
\text { variable }\end{array}$ & $\begin{array}{l}\text { Independent } \\
\text { variable }\end{array}$ & Association & $F$ & $\mathrm{p}$ & $\begin{array}{c}\text { Model R }^{2} \\
(\times 100)\end{array}$ \\
\hline No. of taxa & Sand ripple $\lambda$ & Negative & 14.96 & 0.008 & 71.37 \\
\hline No. of ind. & Sand ripple $\lambda$ & Negative & 7.66 & 0.03 & 56.07 \\
\hline Diversity & Sand ripple $\lambda$ & Negative & 10.09 & 0.02 & 62.72 \\
\hline Evenness & None & - & - & - & - \\
\hline
\end{tabular}

variability among stations, none was significant at $\mathrm{p}<0.05$. No variables significantly explained the variability in evenness among stations.

Sediment characteristics were important in influencing the composition of invertebrate assemblages at the 8 carbonate sediment stations (Table 8). Variance in the mean percent of macrophagous polychaetes per core at the stations was explained largely by mean $\phi$ size. A strong positive relationship exists between mean grain size and percent composition of macrophagous polychaetes. Conversely, the percent composition of microphagous polychaetes is negatively associated with mean grain size. Exposure negatively influenced the percent composition of gastropods in the community and depth explained much of the variability in the percentage of bivalves. No variables measured significantly explained the difference in percent composition of crustaceans or echinoderms.

\section{DISCUSSION}

Direct comparison of the composition of the softbottom community of Hanalei Bay with that reported from previous research conducted in Hawaii is difficult because of the differences in methodology and habitats investigated. Bailey-Brock $(1979,1984)$ found a very different community inhabiting the sandy habitat of a partially sheltered fringing reef on the leeward side of Oahu. The forereef areas of Hawaiian fringing reefs are high energy environments, but wave energy reaching sand and rubble accumulations on backreef flats is greatly diminished compared to that found on the predominantly exposed habitat of Hanalei Bay. Although the composition of polychaete assemblages in sandy backreef areas between polychaete mounds appears to be generally similar to the composition in Hanalei at the familial level, the large densely populated chaetopterid mounds, which characterized the fringing backreef sand habitat, were not present in Hanalei. McCarthy (1996) found syllids and pisionids to be dominant taxa in shallow-water (8 to $20 \mathrm{~m}$ ) reef sediments of sand channels off the south (leeward) shore of Oahu. These polychaetes were also numerically abundant at the coarse sand stations in Hanalei. Estimates of mollusc densities on Oahu are similar to those in this study, but small crustaceans, such as copepods and ostracods, appear to occur in much higher densities off Oahu. Nemerteans and flatworms, which were also abundant in McCarthy's samples, were absent or rare in samples from Hanalei.

The sediment and fauna associated with the muddy habitat at Stn 4 was most distinct. Stn 4 sediments had the smallest mean grain size $(\phi=3.52)$, the lowest percentage of $\mathrm{CaCO}_{3}(21.36 \%)$ and the highest percentage of organic carbon $(4.02 \%)$ and silt content $(38.19 \%)$. This unique sediment harbored an assemblage with the lowest taxonomic richness, number of individuals and diversity per core. The assemblage was characterized by the absence of gastropods and echinoderms, a very low percentage of crustaceans and a much higher percentage of 'other' taxa. This habitat appeared to favor large deposit-feeding organisms, especially acorn worms and sipunculans. The deposit-feeding polychaetes, Magelonidae, were the largest component of the polychaete fauna, but the large macrophagous tubicolous Onuphidae were also important.

Table 8. Statistically significant results of stepwise multiple linear regression analyses for numerical abundance of 6 major taxonomic groups, each as a percentage of all individuals in the invertebrate assemblage. Five independent habitat variables (listed in Table 6) were available for the model

\begin{tabular}{|c|c|c|c|c|c|c|}
\hline $\begin{array}{l}\text { Dependent } \\
\text { variable }\end{array}$ & $\begin{array}{l}\text { Independent } \\
\text { variable }\end{array}$ & Association & $F$ & $\mathrm{p}$ & $\begin{array}{l}\text { Partial R }{ }^{2} \\
\quad(\times 100)\end{array}$ & $\begin{array}{l}\text { Model R2 } \\
(\times 100)\end{array}$ \\
\hline \multirow[t]{2}{*}{ Macrophagous polychaetes } & Mean $\phi$ & Negative & 47.45 & $<0.001$ & 88.78 & 88.78 \\
\hline & Carbon (\%) & Negative & 10.76 & 0.022 & 7.66 & 96.44 \\
\hline Microphagous polychaetes & Mean $\phi$ & Positive & 137.15 & $<0.001$ & 95.81 & 95.81 \\
\hline Crustaceans & None & - & - & - & - & - \\
\hline Gastropods & Sand ripple $\lambda$ & Negative & 19.51 & 0.005 & 76.48 & 76.48 \\
\hline Bivalves & Water depth & Positive & 8.37 & 0.028 & 58.24 & 58.24 \\
\hline Echinoderms & None & - & - & - & - & - \\
\hline
\end{tabular}


Our results suggest that community structure and composition vary continuously along environmental gradients. Within the primarily carbonate sediments, mean grain size and wave exposure appear to be important influences on the community. The number of individuals was significantly correlated with mean grain size (Table 6), and significant negative relationships were detected between relative wave exposure (as estimated by sand ripple wavelength) and taxonomic richness, number of individuals, and diversity (Table 7). These strong relationships suggest that, in Hanalei Bay, physical processes exert a very important influence on assemblage structure. Furthermore, none of the common and conspicuous characteristics of systems dominated by effects of biological interactions are evident. Riddle (1988) observed more diverse assemblages in protected lagoons than on exposed reef flats. Hughes \& Gamble (1977) also found low productivity and species diversity associated with mobile sand bars relative to more stable sandy habitats. Aller \& Dodge (1974) related infaunal diversity and distribution patterns to a gradient of bottom stability. In temperate sedimentary communities, increasing species richness may be associated with decreasing exposure to wave energy (Oliver et al. 1980). At some low level of disturbance from wave energy, biological processes, such as biogenic alteration of sedimentary properties, should become important in influencing assemblage structure (Probert 1984). The stations at Hanalei Bay with lowest wave exposure may approach such a threshold, but fecal pellet accumulation, extensive tube-building, and bioturbation (e.g. callianassid mounds) - processes associated with biogenic alteration of sediments - did not appear to be important in this habitat.

While it is widely recognized that sediment characteristics, especially grain size, influence community structure and composition in temperate systems, the relationship between grain size and invertebrate communities remains unclear for tropical carbonate sediments. In tropical lagoonal carbonate sediments, some researchers have discovered increasing richness and abundance with increasing grain size among meiofaunal assemblages (St. John et al. 1989), macrofaunal assemblages (Jones 1984, Villiers 1988), deposit-feeding gastropods (Skilleter 1992), and vertically migrating zooplankton (Alldredge \& King 1977). The trend in Hanalei Bay of decreasing taxonomic richness and number of individuals with increasing mean grain size appears inconsistent with these previous studies, but no published studies of invertebrate communities in a similar habitat to that found in Hanalei Bay (i.e. exposed coastline) are available. The physical disturbance caused by wave energy in the coarse-grained habitats at Hanalei appears to be a more important influence on assemblage structure than that produced by grain size alone in relatively protected habitats elsewhere. But because exposure and grain size are confounded (e.g. Table 3), clear interpretation of animal-sediment relationships is difficult.

Despite the importance of wave exposure to assemblage structure, mean grain size of the sediment appears to be an important factor influencing assemblage composition. Macrophagous and microphagous polychaetes have significant, but opposite, associations with grain size (Table 8). In addition, microphagous polychaetes were significantly negatively correlated with exposure (Table 6). Two of the numerically dominant microphagous polychaete taxa collected, Paraonidae and Magelonidae, are motile surface deposit feeders and are likely to be affected by sediment instability associated with the coarse-grained habitat; both taxa were absent from the 2 coarsegrained high exposure stations. The most abundant macrophagous polychaete taxon, the family Syllidae, are tiny highly motile sub-surface burrowers that prey upon interstitial meiofauna or eat bits of algae. Syllids dominated the coarse-grained high exposure habitat and were absent or rare at stations with fine-grained sediments. In the most exposed coarse-grained habitat, Stn 2, Pisionidae were abundant. The most common species collected, Pisionidens indica, is known from surf-washed beaches and exhibits adaptations, such as the absence of setae and a burrowing life style, which allow exploitation of high energy habitats (Day 1967, Bailey-Brock 1987).

No habitat variable measured could explain the variation in percent composition of crustaceans in the sedimentary habitats. Jones (1984) found a significant correlation between benthic crustacean species richness and median $\phi$ (fine sediments had fewer species than coarse sediments), but found no relationships between other crustacean assemblage attributes and habitat variables in the lagoonal sands on the Great Barrier Reef (GBR). Along a gradient of increasing wave exposure, Oliver et al. (1980) found a corresponding increasing importance of crustaceans in the community. In Hanalei Bay, no taxon of crustaceans showed a clear affinity for any sedimentary habitat. Ostracods and callianassid shrimp were least common at the coarsegrained, highly exposed stations, but consistent patterns within the crustaceans were not apparent. This could be due in part to the tendency of many crustaceans to engage in nocturnal vertical migrations into the water column (Alldredge \& King 1977, Hobson \& Chess 1978, Jacoby \& Greenwood 1988). The lack of distinct groups of taxa corresponding to particular habitats may be due to horizontal movement in the water column and indiscriminate return to the closest available substratum. 
The percentage of gastropods in the community was significantly negatively correlated with grain size, grain-size standard deviation, and exposure, and positively correlated with the percentage of organic carbon. Linear regression showed that most of the variation in the percentage of gastropods in the community was explained by level of exposure. The percentage of bivalves in the community increased significantly with water depth and was also correlated negatively with grain size. Jones et al. (1990) studied the molluscs of a lagoon on the GBR and found that zones of peak abundance differed among species. Species-specific habitats were not detected at Hanalei Bay. All gastropods showed similar trends in abundance and percent composition in the community, as did bivalves. Gastropods and bivalves were absent from the shallow high exposure station. Despite a general trend of increasing species richness from fine to coarse sediments, Jones et al. (1990) found the lowest numbers of species in a very shallow coarsegrained habitat zone.

Except for a few important studies, most research of coral reef ecology has ignored infaunal soft-sediment communities and focused on the hard substrates of reefs and the associated benthic megafauna. Open sand flats of exposed coastlines provide extensive benthic habitat, and the invertebrate communities of these habitats may provide important inputs to reef systems at higher trophic levels, including significant support of reef-associated fish populations (Parrish \& Zimmerman 1977, DeFelice \& Parrish, unpubl.). Future research expanding on these results should take into account the seasonality of surf energy on wave exposed shores. It is not clear whether the patterns observed in the relatively calmer summer months of this study persist throughout the year.

Acknowledgements. Funding for this research was provided by the Hawaii Cooperative Fishery Research Unit through a grant to J.D.P. from the Hawaii Department of Land and Natural Resources, Division of Aquatic Resources. J. Bailey-Brock and E. A. Kay provided advice during this study and reviewed earlier drafts of this manuscript. J. Frederick and J. Peterson assisted in the field, and the Hanalei Bay Resort and Kauai National Wildlife Refuge Complex (US Fish and Wildlife Service) provided logistical support. Special thanks to A. Friedlander for support in the field and valuable criticisms regarding all aspects of this research. This research partially fulfilled the requirements for a Masters Degree in Zoology from the University of Hawaii, Honolulu to R.C.D.

\section{LITERATURE CITED}

Alldredge AL, King JM (1977) Distribution, abundance, and substrate preferences of demersal reef zooplankton at Lizard Island Lagoon, Great Barrier Reef. Mar Biol 41: $317-333$
Aller RC, Dodge RE (1974) Animal-sediment relations in a tropical lagoon, Discovery Bay, Jamaica. J Mar Res 32: 209-232

Andrew NL, Mapstone BD (1987) Sampling and the description of spatial pattern in marine ecology. Oceanogr Mar Biol Ann Rev 25:39-90

Bailey-Brock JH (1979) Sediment trapping by chaetopterid polychaetes on a Hawaiian fringing reef. J Mar Res 37 : 643-656

Bailey-Brock JH (1984) Ecology of the tube-building polychaete Diopatra leuckarti Kinberg 1865 (Onuphidae) in Hawaii: community structure, and sediment stabilizing properties. J Linn Soc Lond Zool 80:191-199

Bailey-Brock JH (1987) Phylum Annelida. In: Devaney DM, Eldredge LG (eds) Reef and shore fauna of Hawaii: sections 2 and 3. Bishop Museum Press, Honolulu, p 213-454

Birtles A, Arnold P (1983) Between the reefs: some patterns of soft substrate epibenthos on the Central Barrier Reef Shelf. Inaugural Great Barrier Reef Conference, Townsville, p 159-163

Brock RE, Smith SV (1983) Response of coral reef cryptofauna communities to food and space. Coral Reefs 1:179-183

Brown AC, McLachlan A (1990) Ecology of sandy beaches. Elsevier Science Publishers, Amsterdam

Davies AG (1984) Field observations of wave-induced motion above the seabed and of the resulting sediment movement. Rep 179, Institute of Oceanographic Sciences, Taunton

Day JH (1967) A monograph on the Polychaeta of southern Africa. British Museum of Natural History, London

Fauchald K, Jumars PA (1979) The diet of worms: a study of polychaete feeding guilds. Oceanogr Mar Biol Ann Rev 17:193-284

Gray JS (1981) The ecology of marine sediments. Cambridge University Press, Cambridge

Hobson ES, Chess JR (1978) Trophic relationships among fishes and plankton in the lagoon at Enewetak Atoll, Marshall Islands. Fish Bull 76:133-153

Hughes RN, Gamble JC (1977) A quantitative survey of the biota of intertidal soft substrata on Aldabra Atoll, Indian Ocean. Phil Trans R Soc Lond 279:327-355

Jacoby CA, Greenwood JG (1988) Spatial, temporal, and behavioral patterns in emergence of zooplankton in the lagoon of Heron Reef, Great Barrier Reef, Australia. Mar Biol 97:309-328

Jones AR (1984) Sedimentary relationships and community structure of benthic crustacean assemblages of reef-associated sediments at Lizard Island, Great Barrier Reef. Coral Reefs 3:101-111

Jones GP, Ferell DJ, Sale PF (1990) Spatial pattern in the abundance and structure of mollusc populations in the soft sediments of a coral reef lagoon. Mar Ecol Prog Ser 62: $109-120$

Jones GP, Ferrell DJ, Sale PF (1992) Fish feeding and dynamics of soft-sediment mollusc populations in a coral reef lagoon. Mar Ecol Prog Ser 80:175-190

Kovach WI (1993) MVSP - A multivariate statistical package for IBM-PC's, version 2.1. Kovach Computing Services, Pentraeth, Wales, UK

Lindholm RC (1987) A practical approach to sedimentology. Allen \& Unwin Ltd, Sydney

McCarthy SA (1996) Patterns of spatial and temporal variability in Hawaiian soft bottom benthos. PhD Dissertation, Dept Oceanography, University of Hawaii, Honolulu

Miller MC, Komar PD (1980) A field investigation of the relationship between oscillation ripple spacing and the nearbottom water orbital motions. J Sed Petrol 50:183-191 
Oliver JS, Slattery PN, Hulberg LW, Nybakken JW (1980) Relationships between wave disturbance and zonation of benthic invertebrate communities along a subtidal highenergy beach in Monterey Bay, California. Fish Bull 78: $437-454$

Parrish JD, Zimmerman RJ (1977) Utilization by fishes of space and food resources on an offshore Puerto Rican coral reef and its surroundings. Proc 3rd Int Coral Reef Symp Miami, p 297-303

Pearson TH, Rosenberg R (1986) Feast and famine: Structuring factors in marine benthic communities. In: Gee JHR, Giller PS (eds) Organization of communities: past and present. Blackwell Scientific Publications, London

Pielou EC (1977) Mathematical ecology. John Wiley and Sons, New York

Probert PK (1984) Disturbance, sediment stability, and trophic structure of soft-bottom communities. J Mar Res 42: 893-921

Riddle MJ (1988) Patterns in the distribution of macrofaunal communities in coral reef sediments on the central Great Barrier Reef. Mar Ecol Prog Ser 47:281-292

SAS Institute, Inc (1996) SAS/STAT, Version 6 software: changes and enhancements through release 6.11, Cary, NC

Sherman KM, Reidenauer JA, Thistle D, Meeter D (1983) Role of a natural disturbance in an assemblage of marine freeliving nematodes. Mar Ecol Prog Ser 11:23-30

Skilleter GA (1992) Recruitment of cerithiid gastropods (Rhinoclavis spp.) in sediments at One Tree Reef, Great Barrier Reef. J Exp Mar Biol Ecol 156:1-21

Sorden CT (1982) Trophic relationships of goatfishes (Family Mullidae) in the Northwestern Hawaiian Islands. MS

Editorial responsibility: Charles Birkeland (Contributing Editor), Honolulu, Hawaii, USA
Thesis, Dept Zoology, University of Hawaii, Honolulu St. John J, Jones GP, Sale PF (1989) Distribution and abundance of soft-sediment meiofauna and a predatory goby in a coral reef lagoon. Coral Reefs 8:51-57

Suchanek TH, Colin PL (1986) Rates and effects of bioturbation by invertebrates and fishes at Enewetak and Bikini Atolls. Bull Mar Sci 38:25-34

Taylor JD (1971) Reef-associated molluscan assemblages in the western Indian Ocean. Symp Zool Soc Lond 28: 501-534

Thomassin BA (1978) Soft-bottom communities. In: Stoddart DR, Johannes RE (eds) Coral reefs: research methods. UNESCO, Paris, p 263-298

Thomassin BA, Vivien MH, Vitiello P (1976) Distribution de la meiofaune et de la macrofaune des sables coralliens de la retenue d'eau epirecifale du Grand Recif de Tulear (Madagascar). J Exp Mar Biol Ecol 22:31-53

Thomassin BA, Jouin C, Renaud-Mornant J, Richard G, Salvat B (1982) Macrofauna and meiofauna in the coral sediments on the Tiahura Reef complex, Moorea Island (French Polynesia). TETHYS 10:392-397

Villiers L (1988) Density and biomass of macro- and meiofauna in lagoon sands at Mururoa Atoll, French Polynesia. Proc 6th Int Coral Reef Symp Australia, 2:45-51

Whitlach RB (1981) Animal-sediment relationships in intertidal marine benthic habitats: some determinants of deposit-feeding species diversity. J Exp Mar Biol Ecol 53: 31-45

Woodin SA (1983) Biotic interactions in recent marine sedimentary environments. In: Tevesz MJS, McCall PL (eds) Biotic interactions in recent and fossil benthic communities. Plenum Press, New York, p 3-38

Submitted: March 14, 2000; Accepted: August 22, 2000

Proofs received from author(s): April 30, 2001 